\title{
Analysis of Laser Processing of Artificial Leather
}

\author{
Pavels Narica \\ Engineering faculty \\ Rezekne Academy of Technologies \\ Rezekne, Latvia \\ Pavels.Narica@rta.lv \\ Silvija Mežinska \\ Engineering faculty \\ Rezekne Academy of Technologies \\ Rezekne, Latvia \\ Silvija.Mezinska@rta.lv
}

\author{
Ruta Laizāne \\ Engineering faculty \\ Rezekne Academy of Technologies \\ Rezekne, Latvia \\ Ruta.Laizane@rta.lv
}

\author{
Antons Pacejs \\ Engineering faculty \\ Rezekne Academy of Technologies \\ Rezekne, Latvia \\ Antons.Pacejs@rta.lv
}

\begin{abstract}
With the development of laser technologies, the field of application of lasers is developing as well. They are capable of processing numerous materials and are still finding their application in unexpected areas. In this case, lasers are studied as a system with which black and white color artificial leather can be processed. This modern material allows you to combine comfort, practicality and reasonable price in a finished product. The manufacturer of artificial leather provides wide possibilities of design. In this study laser beam was used for dark and light laser markings on black and white color artificial leather and in this work, it could be observed how $\mathrm{CO}_{2}$ and fiber laser processing influence this specific material.
\end{abstract}

Keywords-Artificial leather, CO2 laser, Fiber laser, laser processing.

\section{INTRODUCTION}

\section{A. Marking}

Product labeling is an important process in modern production. It provides control over the quantity and quality of the products produced. For the manufacturer, labeling is required for product lobbying and as additional protection against counterfeiting attempts, for the consumer to obtain information on the product and as a guarantee of quality control. Laser labeling is becoming more widespread as a result of the rapid development of this industry and its integration into other industries [1]. Fast and accurate scanning of products on different materials is one of the main advantages of this technology [2].

There are lots of ways how to apply information on the products and some of them are: pad printingindirect printing of paints on the flat and convex surfaces of products made of plastic, wood, cardboard, etc. with a silicone tampon, direct full-color printing on fabric with water ink - direct printing on textiles, which does not require preparatory procedures, this method allows you to apply full-color images to T-shirts, polos and hoodies, print on complex surfaces (seams, slats, etc.), getting a

stable and colorful raster image with high resolution, machine embroidery images on textiles and fabric chevrons - the most persistent type of imaging on textiles, the choice of colors is limited by the color palette of the threads themselves, but the logo on T-shirts, hoodies, hats, jackets and shirts will not be erased and will remain bright [3] as well as shock-mechanical, electro erosion, electrochemical, powder coating and laser marking etc.

\section{B. Laser processing}

Contactless method has high scanning accuracy, fast scanning speed and a clear pattern, the ability to scan all kinds of texts, symbols, patterns on flat and convex surfaces, hard, soft and fragile products. The laser scanning machine integrates all the advantages of laser cutting, marking and engraving, which makes it possible to scan small and complex patterns on numerous materials [1].

Laser scanning has been used for decades, but it has become very common in recent years. Before we start let's remember what were: laser marking, engraving and cutting. The basic schematics view of those processing methods could be observed in Fig.1.

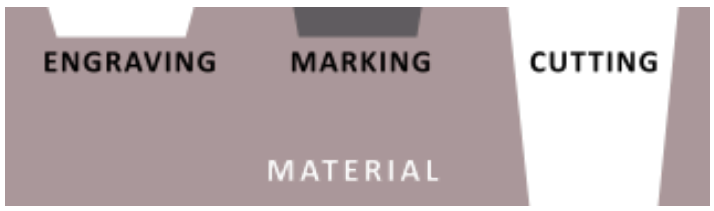

Fig. 1. Schematic view of laser cutting, engraving and marking processes.

The technology of cutting materials using lasers are commonly used in industrial production lines. A focused laser beam, usually controlled by a computer, provides a high energy density and allows to cut almost any material, regardless of their thermophysical properties using different laser sources.

When engraving, the laser beam changes the structure of the material. Under the influence of a laser, cavities 
open and irregularities form on surfaces, and the impact zone itself is visible to the naked eye. The laser beam creates heat at the point of impact and causes the fibers to evaporate. This is a quick process, and the image is clear, and all the irregularities are well felt during the touch. The more passes, or the higher power and slower speed are set, what causes increasing in energy density, the deeper laser engraving is made during the treatment.

In the process of marking under the influence of a laser, the surface of the material slightly changes its properties or appearance. The material itself in the process of marking does not hugely change its original properties, because of the local laser treatment. On the one hand, for metals slight heat provokes oxidation and changing reflectance of the light of the areas of impact, and the surface itself is not damaged, but on the other hand, laser marking of no-conductive materials causes the changes in surface of the material so the spot of the impact causes for material to change color.

\section{MATERIALS AND METHODS}

\section{A. Material}

Currently, the genuine leather industry is facing severe pressure from multiple sources, including scarcity of raw hides, environmental pollution, and growing ethical concern over animal rights. Thus, to meet the escalating demand for leather products worldwide, the design and manufacture of leather substitutes, or artificial leather, are springing up, especially in Southeast Asia [4].

Artificial leather has been used for decades as an essential element of clothing design. The reason for designing faux fabrics are: the lower cost of the material; the ease of cutting and sewing; the fact that they are more available than leather or suede; no irregularities on the fabric surface, common in natural materials; and animal treatment and environment concerns. They are also designing to go beyond the limitations of leather and suede by creating "unnatural" colors and textures. [5].

There are many names for artificial leather: faux leather, fake leather, leatherette, synthetic leather, imitation leather, manmade leather etc. The adjective "artificial", initially subconsciously associated with the phrases "not real", "fake", has long acquired a somewhat different meaning. So, the concept of "artificial leather" over the past decades has absolutely nothing to do with the notion "product of inadequate quality."

The two main differences between the natural material and faux material are: faux leather is nonporous, so the fabric does not allow the air to pass though; fabric backing is required to support the embossed plastic face. Usual fiber content - face: usually polyurethane (PU) or polyvinylchloride (PVC) film; polyester film, which is recyclable may be available; backing depending on the purpose of use: non-woven fabric, $100 \%$ polyester interlock knit or polyester/cotton blend square plain weave Weaknesses: not breathable; dry-cleaning chemical may damage or destroy plastic film; cannot be re-sewn, needle holes cannot be repaired; plastic surface may cause "noise" or adhere together easily; extremely heat-sensitive [4].

PVC is the most commonly used polymer in the manufacture of faux leather because of its high durability and low cost. PVC is water-durable, crack resistant at room temperature, and resilient to wear and tear due to its chemical properties. PU feels more like genuine leather and is lighter than PVC, but PU leather is about twice as expensive as PVC leather, making it cost-prohibitive for many producers of low-margin consumer goods [6].

As a new polymeric material, synthetic leather is an important material for making shoes, bags, accessories, jackets, trousers and shirts suitcases and decorations. With the advancement and application of new processes and technologies, synthetic leather develops an advantage unparalleled by natural leather in aspects of variety, design and color, style, price and performance [7].

Various structural effects, colors and thicknesses are produced using PVC and PU. PU skin is considered to be more environmentally friendly compared to vinyl base because it does not produce dioxins. Artificial leather has a wide range of applications in the textile industry for technical textiles, different color material could be observed in Fig.2. There are areas where artificial skin is better suited because it is more resistant to the constant exposure to sunlight and water, which damages the natural skin [8].

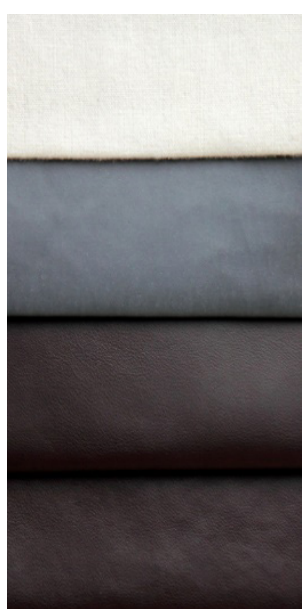

Fig. 2. Different shades of artificial leather

The structure of the base material and coating layer could be observed in Fig.3. In this study two different color (black and white) artificial leather was used to implement high marking contrast possibilities on the material.
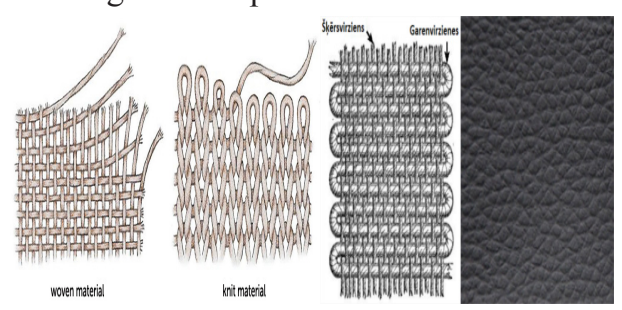

Fig. 3. Polyester interlock knit base fiber structure (with weft and warp fiber direction) and PVC, PU black color coating.

Fabric type - artificial leather: 1) Black color artificial leather composition coating PU 100\%, backing 90\% polyester, $6 \%$ Cotton, $4 \%$ Viscose, weight $- \pm \mathbf{5 5 5} \pm \mathbf{5} \mathbf{g} / \mathbf{m}^{2}$, thickness $0,9-1 \mathrm{~mm}$, width $\pm \mathbf{1 4 0} \pm \mathbf{2} \mathbf{~ c m}$, fire resistance 
BS 5852, Abrasion resistance $>45000$ ISO 12947-2, resistance on light xenon test 7 (scale 1-8), resistance to sebum good.

2) White color artificial leather -composition coating 95\% PVC 5\% PU, backing 100\% polyester, weight - \pm $\mathbf{4 3 0} \pm \mathbf{5} \mathbf{g} / \mathbf{m}^{2}$, thickness $0,7 \mathrm{~mm}$, width $140 \pm 2 \mathrm{~cm}$, fire resistance BS 5852, Martindale Abrasion resistance > 100.000 cycles ISO 12947-2, Color Fastness to Light 4 (scale 1-5) ISO 105-B02, resistance to sebum good.

\section{B. Laser systems}

Laser radiation is a type of physical energy that is not found in natural light sources. This is achieved by special devices - optical quantum generators of various types and structures. All lasers consist of three basic components: active medium, pumping system (power source), optical resonator (in the case when the laser is working as an amplifier, the optical resonator is not used). Each of these components fulfills the specific functions of laser operation.

The aim of this paper is to achieve potentiality acceptable contrast markings on the material by the laser processing without causing a significant change of the material structure. To operate with a marking laser system mostly the following parameters should be set: power regulation coefficient, scanning speed, line step as well as for the impulse laser systems pulse- repetition frequency can be changed as well. As we know that each set of parameters applied to the material could change the outcome. So, there exist a lot of combination which can be managed.

1) CHANXAN $C X-20 G$ laser system specifications are:

- $\quad$ Laser type - Nd:Yag fiber laser;

- Operating mode - impulse;

- Wavelength - 1064 [nm];

- Working range - 300x300 [mm];

- Focal spot diameter $\sim 20[\mu \mathrm{m}]$.

Laser system technical parameters can be observed in Table 1. and schematic view of experimental set-up could be observed in Fig.4.

TABLE 1 CHANXAN CX-20G LASER TECHNICAL PARAMETERS

\begin{tabular}{|l|l|l|l|l|}
\hline \multicolumn{1}{|c|}{ Symbol } & \multicolumn{1}{c|}{ Name } & \multicolumn{1}{c|}{ Values range } & \multicolumn{1}{c|}{ Step } & \multicolumn{1}{c|}{ Units } \\
\hline$v$ & Scan speed & $1-10000$ & 1 & $\mathrm{~mm} / \mathrm{s}$ \\
\hline$\Delta \mathrm{f}$ & Focus shift & $-100-100$ & 0.1 & $\mathrm{~mm}$ \\
\hline$k P$ & $\begin{array}{l}\text { Power regu- } \\
\text { lation coeffi- } \\
\text { cient }\end{array}$ & $0-100$ & 0.1 & $\%$ \\
\hline$P$ & $\begin{array}{l}\text { A v a r e g e } \\
\text { power }\end{array}$ & $0-20$ & $\mathrm{~W}$ & $\mathrm{kHz}$ \\
\hline$f$ & Frequency & $20-50$ & 1 & \\
\hline
\end{tabular}

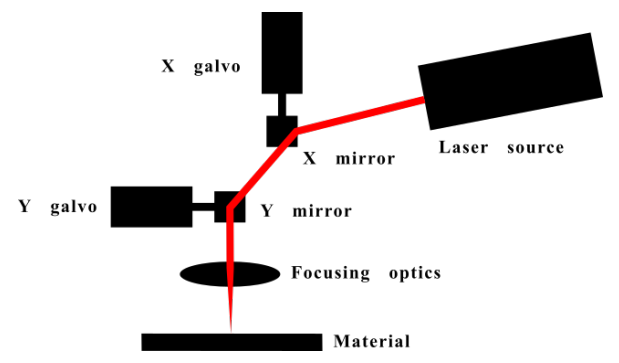

Fig. 4. Schematic view of experimental set-up of CHANXAN CX-20G fiber laser system.

In Fig.5 it could be seen that coloration between laser $k P$ parameter for average output power $P$ for fiber laser is almost linear.

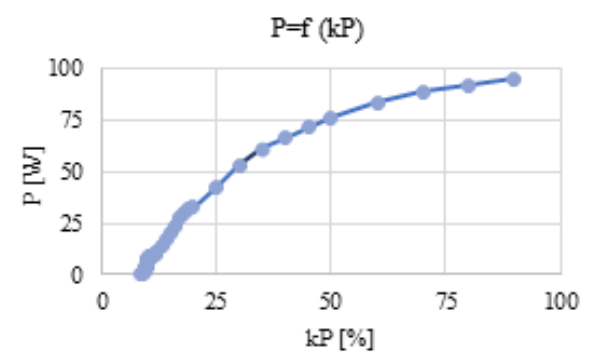

Fig. 5. Mapping of values of power regulation coefficient $\mathrm{kP}[\%]$ to fiber laser power $\mathrm{P}[\mathrm{W}]$ with a constant pulse repetition frequency $\mathrm{f}=30[\mathrm{kHz}]$.

2) SUNTOP ST-CC9060 laser system specifications are:

- Laser type - CO2 gas laser;

- Operating mode - continuous wave;

- Wavelength - $10060[\mathrm{~nm}]$;

- Working range - 900x600 [mm];

- Focal spot diameter $\sim 80[\mu \mathrm{m}]$. Laser system technical parameters can be observed in Table 2 and schematic view of experimental setup could be observed in Fig.6.

TABLE 2 SUNTOP ST-CC9060 LASER TECHNICAL PARAMETERS.

\begin{tabular}{|l|l|l|l|l|}
\hline \multicolumn{1}{|c|}{ Symbol } & \multicolumn{1}{c|}{ Name } & \multicolumn{1}{c|}{ Values range } & \multicolumn{1}{c|}{ Step } & \multicolumn{1}{c|}{ Units } \\
\hline$v$ & Scan speed & $1-400$ & 1 & $\mathrm{~mm} / \mathrm{s}$ \\
\hline$\Delta \mathrm{f}$ & Focus shift & $-50-50$ & 0.1 & $\mathrm{~mm}$ \\
\hline$k P$ & $\begin{array}{l}\text { Power regu- } \\
\text { lation coeffi- } \\
\text { cient }\end{array}$ & $0-100$ & 0.1 & $\%$ \\
\hline$P$ & $\begin{array}{l}\text { A v a r e g e } \\
\text { power }\end{array}$ & $0-100$ & & $\mathrm{~W}$ \\
\hline
\end{tabular}

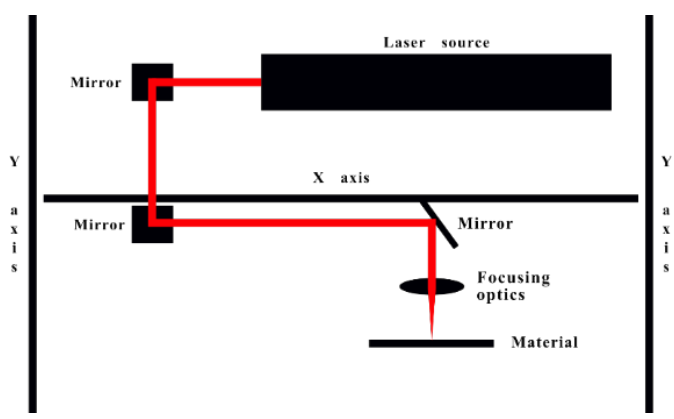

Fig. 6. Schematic view of experimental set-up of SUNTOP ST$\mathrm{CC} 9060 \mathrm{CO}_{2}$ laser system. 
In Fig.7. it could be observed that coloration between laser $k P$ parameter for average output power $P$ is something similar to exponential and one more thing was noted that those kind of $\mathrm{CO}_{2}$ systems generate laser beam only after specific $k P$ value. In this case it was 8 [\%].

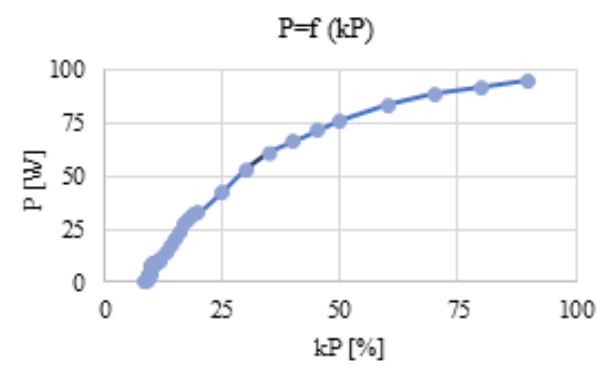

Fig. 7. Mapping of values of power regulation coefficient $k P[\%]$ to

\section{Output power measurements} $\mathrm{CO} 2$ laser power $P[\mathrm{~W}]$

The active medium is what determines the wavelength of the lasers itself, that often determines how the material will behave due to laser processing. It has been noted that power regulation coefficient $k P \%$. could be set in the laser system software, but for better process understanding and for further optimization of parameters it is better to carry out power measurements of a laser output power (could be used any suitable power measurements system or output power measurements could be defined by the manufacturer) in our case it was power measurement sensor OPHIR F150A-BB-26 that is shown in Fig.8. and its specifications are summed up in Table 3.

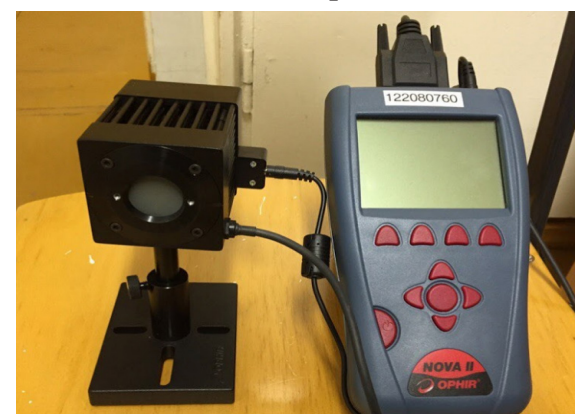

Fig. 8. Power measurement sensor OPHIR F150A-BB-26

TABLE 3 POWER MEASUREMENT SENSOR OPHIR F150A-BB-26 SPECIFICATIONS

\begin{tabular}{|l|l|}
\hline Name & Values \\
\hline Absorber Type & Broadband \\
\hline Spectral Range $[\mu \mathrm{m}]$ & $0.19-20$ \\
\hline Aperture diameter $[\mathrm{mm}]$ & 26 \\
\hline Power Range $[\mathrm{W}]$ & $0,05-150$ \\
\hline Power Noise Level $[\mathrm{mW}]$ & 3 \\
\hline Max Average Power Density $[\mathrm{kW} / \mathrm{cm} 2]$ & 12 \\
\hline Max Energy Desnity $[\mathrm{J} / \mathrm{cm} 2]$ & 10 \\
\hline Power Accuracy $[+/-\%]$ & 3 \\
\hline Cooling & fan \\
\hline
\end{tabular}

During this study from preliminary experiments it was determinate that artificial leather coating is very heat sensitive material, so there are no needs to use high energy density systems to treat this specific material.

\section{Process parameters}

The upper power limit (and therefore the energy density) of each laser source is preset, and it is necessary to determine the optimal range parameters variation to achieve required results.

However, the power density $\left[\mathrm{W} / \mathrm{mm}^{2}\right]$ is determined by the formula (1), where $S$ is the surface of the laser beam working spot $\left[\mathrm{mm}^{2}\right]$ and $P[\mathrm{~W}]$ output power.

$$
q_{p S}=\frac{P}{S}
$$

Considering, that $\mathrm{S}=\left(\pi \mathrm{d}^{2}\right) / 4$ we get,

$$
q_{p s}=\frac{4 P}{\pi d^{2}}
$$

where $\mathrm{d}[\mathrm{mm}]$ is the diameter of the working spot. This formula will help us understand that by changing (defocusing) laser beam, the power density changes as well. So, for precise measurements this study laser processing experiments was made in focus position, where laser beam has smallest working spot.

In this study laser energy density was described and it is related to delivered total energy $\left[\mathrm{J} / \mathrm{mm}^{2}\right]$ to the target material and in this paper, it helped better characterizing the laser processing and beam impact on the material.

$$
q_{e s}=\frac{P}{d * v}
$$

Where $v$ is the scanning speed $[\mathrm{mm} / \mathrm{s}], \mathrm{d}$ is the diameter of the working spot [mm] and $P$ output power [W].

The goal of this paper is to determine the limits of energy density $\left[\mathrm{J} / \mathrm{mm}^{2}\right]$ for artificial leather treatment using $\mathrm{CO}_{2}$ and fiber laser, where laser processing has:

- Almost imperceptible impact on the material coating layer;

- There is a complete destruction of the material base layer.

Then in that obtained range it will be possible to find the best processing parameters for laser marking of artificial leather using the different values of parameters matrix method.

\section{RESULTS AND DISCUSSIONS}

\section{A. Outcomes from fiber laser processing on white and black color artificial leather}

In Fig. 9., 10. and 11. it could be observed that samples were scanned by the fiber laser in a form of a $4 \times 5$ matrix with each cell having different combination of laser parameters values.

For both white and black color artificial leather was applied this range of parameters:

- $\quad$ Average power $P-1-20[\mathrm{~W}]$;

- $\quad$ Scanning speed $v-300-3000[\mathrm{~mm} / \mathrm{s}]$;

- Line distance $d x-0.01[\mathrm{~mm}]$;

- Pulse repetition frequency $f=30[\mathrm{kHz}]$;

- Focus shift $\Delta \mathrm{f}-0[\mathrm{~mm}]$. 


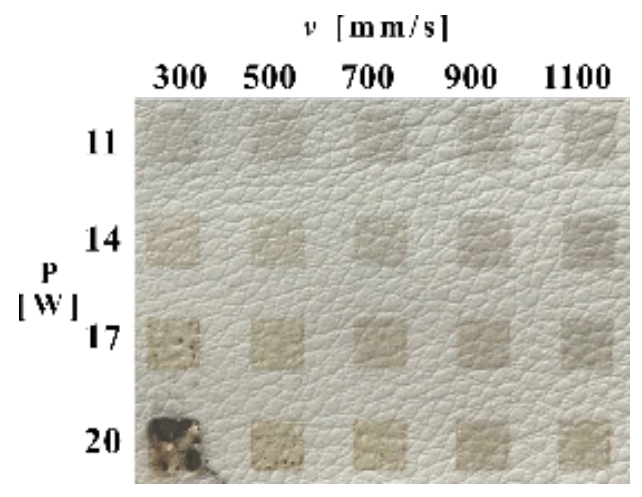

Fig. 9. Outcomes after fiber laser treatment on white color artificial leather material.

$v[\mathrm{~m} \mathrm{~m} / \mathrm{s}]$

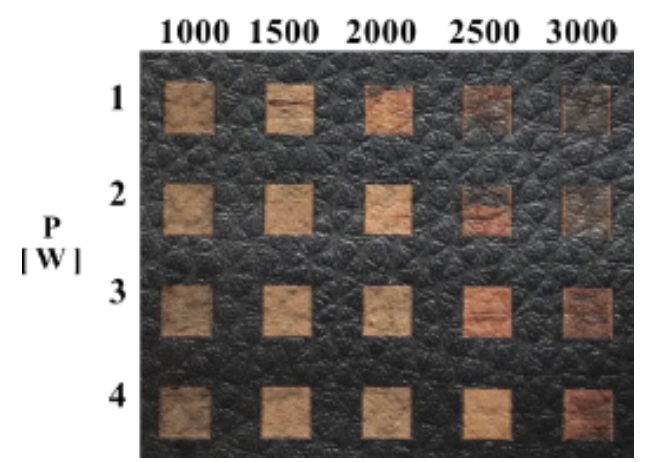

Fig. 10. Outcomes after fiber laser treatment on black color artificial leather material.

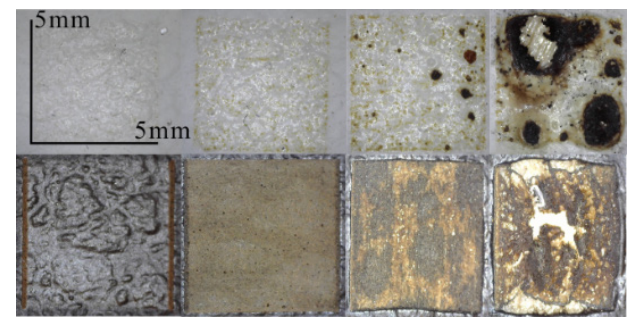

Fig. 11. Material degradation caused by changing energy density applied to the material (Dino-Lite Edge AM7115MZT microscope).

In Table 4 it could be observed the approximate energy density limits using fiber laser system for different material treatment like marking, engraving and cutting on black and white color artificial leather.

TABLE 4 REQUIRED APPROXIMATE ENERGY DENSITY FOR MATERIAL TREATMENT USING FIBER LASER SYSTEM

\begin{tabular}{|l|c|c|}
\hline \multicolumn{1}{|c|}{ Material degradation } & $\begin{array}{c}\text { White color } \\
\text { artificial leather } \\
{\left[\mathrm{J} / \mathrm{mm}^{2}\right]}\end{array}$ & $\begin{array}{c}\text { Black color artificial } \\
\text { leather } \\
{\left[\mathrm{J} / \mathrm{mm}^{2}\right]}\end{array}$ \\
\hline $\begin{array}{l}\text { Slightly visible zone of } \\
\text { impact, coating marked }\end{array}$ & 0.50 & 0.017 \\
\hline $\begin{array}{l}\text { Material has been en- } \\
\text { graved }\end{array}$ & 2.83 & 0.2 \\
\hline Material cut through & 3.33 & 1.33 \\
\hline
\end{tabular}

B. Outcomes from $\mathrm{CO}_{2}$ laser processing on white and black color artificial leather

Fig. 12., 13. and 14. shows that samples were scanned by the $\mathrm{CO}_{2}$ laser in a form of a $4 \times 5$ matrix with each cell having different combination of laser parameters values.

For both white and black color artificial leather was applied same sets of parameters (Fig.2.):

- $\quad$ Average power $P-1-4[\mathrm{~W}]$;
- $\quad$ Scanning speed $v-100-300[\mathrm{~mm} / \mathrm{s}]$

- Line distance $d x-0.1[\mathrm{~mm}]$;

- Focus shift $\Delta \mathrm{f}-0[\mathrm{~mm}]$.

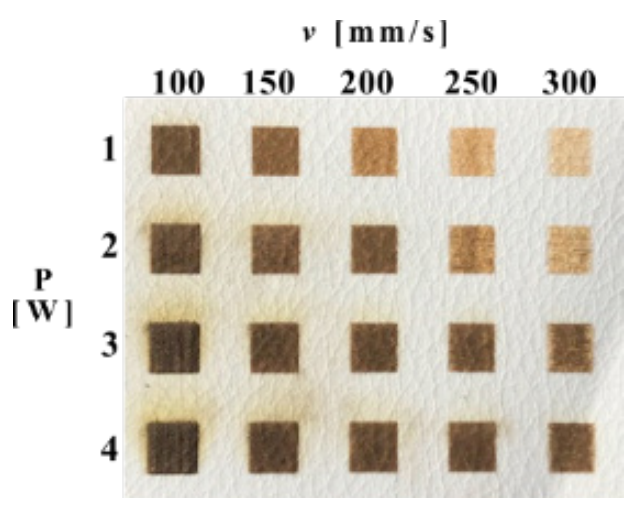

Fig. 12. Outcomes after $\mathrm{CO} 2$ laser treatment on white color artificial leather material.

$v[\mathrm{~mm} / \mathrm{s}]$

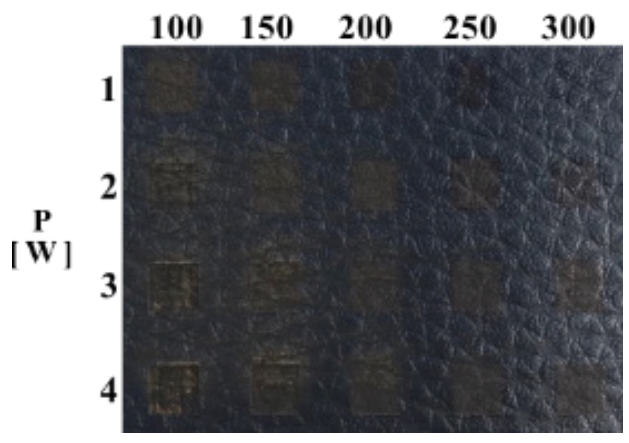

Fig. 13. Outcomes after $\mathrm{CO} 2$ laser treatment on black color artificial leather material.

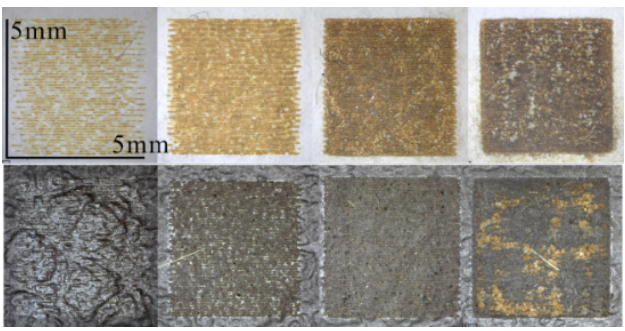

Fig. 14. Material degradation caused by changing energy density applied to the material (Dino-Lite Edge AM7115MZT microscope).

Table 5 demonstrates approximate energy density limits using $\mathrm{CO}_{2}$ laser system for different material treatment like marking, engraving and cutting on black and white color artificial leather.

TABLE 5 REQUIRED APPROXIMATE ENERGY DENSITY FOR MATERIAL TREATMENT USING $\mathrm{CO}_{2}$ LASER SYSTEM

\begin{tabular}{|l|c|c|}
\hline \multicolumn{1}{|c|}{ Material degradation } & $\begin{array}{c}\text { White color } \\
\text { artificial leather } \\
{\left[\mathrm{J} / \mathrm{mm}^{2}\right]}\end{array}$ & $\begin{array}{c}\text { Black color artificial } \\
\text { leather } \\
{\left[\mathrm{J} / \mathrm{mm}^{2}\right]}\end{array}$ \\
\hline $\begin{array}{l}\text { Slightly visible zone of } \\
\text { impact, coating marked }\end{array}$ & 0.13 & 0.0083 \\
\hline $\begin{array}{l}\text { Material has been en- } \\
\text { graved }\end{array}$ & 1.25 & 0.15 \\
\hline Material cut through & 1.67 & 0.70 \\
\hline
\end{tabular}

A. Ultimate tensile strength results and discussions

Ultimate tensile strength is the greatest stress especially 
in tension that a material is capable of withstanding without rupture. In this study ultimate tensile strength of artificial leather were tested and results plotted in graphs and tables. The one of the tasks of the article was to observe influence on the specimens by laser processing on the material in weft and warp directions.

During preparation, black color artificial leather was cutted in weft and warp directions of the fibers with dimensions 50 [mm] x 300 [mm], 6 samples in weft and 6 samples in warp. Then fiber laser marking was applied in the middle of prepared samples with dimensions 50 [mm] x 50 [mm] (Fig. 15. and 16.), 3 samples in weft and 3 samples in warp with applied laser scanning as well as 6 samples for both fiber directions remained unscanned. The ultimate tensile strength test was applied to 4 sample sets (Table 6).

\begin{tabular}{|l|c|}
\hline \multicolumn{1}{|c|}{ Description } & Sample set \\
\hline 3 specimens of artificial leather weft direction & I \\
\hline $\begin{array}{l}3 \text { specimens of artificial leather weft direction } \\
\text { with marking applied }\end{array}$ & II \\
\hline 3 specimens of artificial leather warp direction & III \\
\hline $\begin{array}{l}3 \text { specimens of artificial leather warp direction } \\
\text { with marking applied }\end{array}$ & IV \\
\hline
\end{tabular}

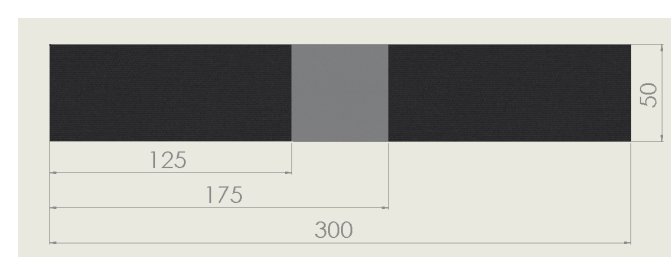

Fig. 15. Schematic drawing of prepaired samples in [mm].

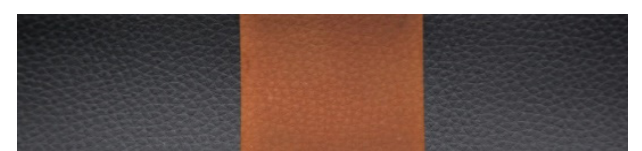

Fig. 16. Obtained laser treatment on artificial leather sample by fiber laser.

In this work was carried the effect of specificly selected input parametrs for laser processing, in this case - marking (contrasted color), on the tensile strength of artificial leather. The aim was to determine how the acceptable contrasted engraving applied to artificail leather impacts on the maximum tensile strength compared to the untreated (control) samples. The test was performed using Zwick / Roell machine (Fig. 17.) and results could be observed in Table 5.

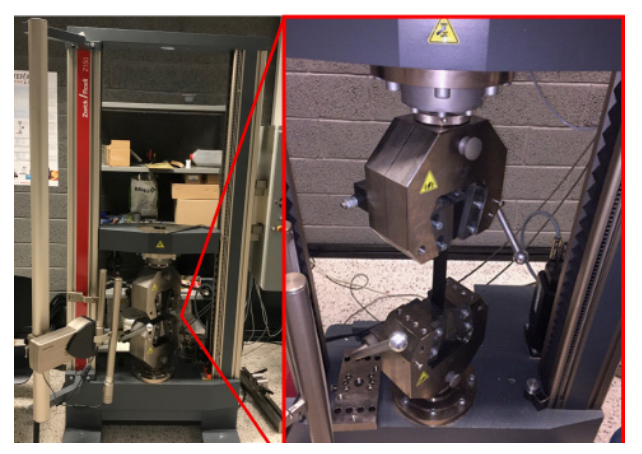

Fig. 17. Ultimate tensile strength testing using Zwick/ Roell machine
TABle. 7 Ultimate tensile STRENGTH Results For ALl SAMPLE SETS.

\begin{tabular}{|c|l|l|l|l|}
\hline $\begin{array}{c}\text { Sample } \\
\text { set }\end{array}$ & $\begin{array}{c}\text { Average } \\
\text { UTS }(\mathrm{N})\end{array}$ & $\begin{array}{c}\text { Maximum } \\
(\mathrm{N})\end{array}$ & $\begin{array}{c}\text { Minimum } \\
(\mathrm{N})\end{array}$ & $\begin{array}{c}\text { Range } \\
(\mathrm{N})\end{array}$ \\
\hline I & 256.89 & 265.29 & 256.89 & 14.88 \\
\hline II & 262.01 & 266.21 & 258.93 & 7.28 \\
\hline III & 457.21 & 496.31 & 431.76 & 64.55 \\
\hline IV & 466.38 & 484.69 & 441.85 & 42.84 \\
\hline
\end{tabular}

We noted that obtained laser treating parameters has no influence on the artificial leather both in weft and warp directions till the base material has not damaged by the laser beam.

From chart in Fig. 18. and test results in Table 7 we can clearly see how applied laser marking influence the artificial leather. On the one hand it could be observed that chosen material has a bigger ultimate tensile strength in weft direction, than in a warp direction and on the other hand we can clearly observe that applied laser marking is not affect the UTS results, because laser treatment was obtained only on the material coating.

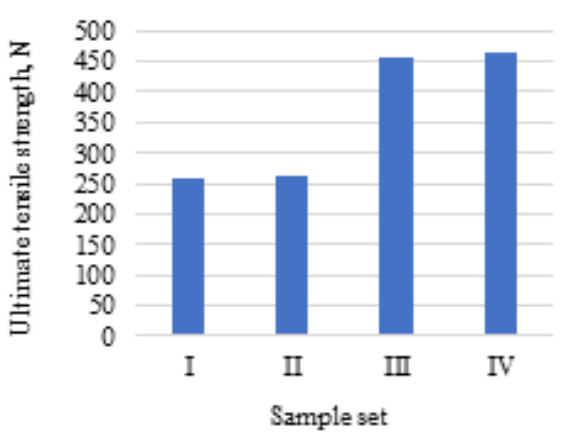

Fig. 18. Average ultimate tensile strength $(\mathrm{N})$ plotted in chart

\section{SumMary}

Due to different absorbtion, reflection and transmission properties by different IR wavelengts of used material it could be observed (Fig 19. and 20.) that in both cases (using fiber and $\mathrm{CO}_{2}$ laser) white color artificial leather is more reflective material to specific IR wavelengths used in this study and energy density requested for treatment like marking, engraving and cutting for black color artificial leather is much less than white color artificial leather. From plotted energy density charts it could be observed that in this work used laser system could be used in marking, engraving and cutting processes.

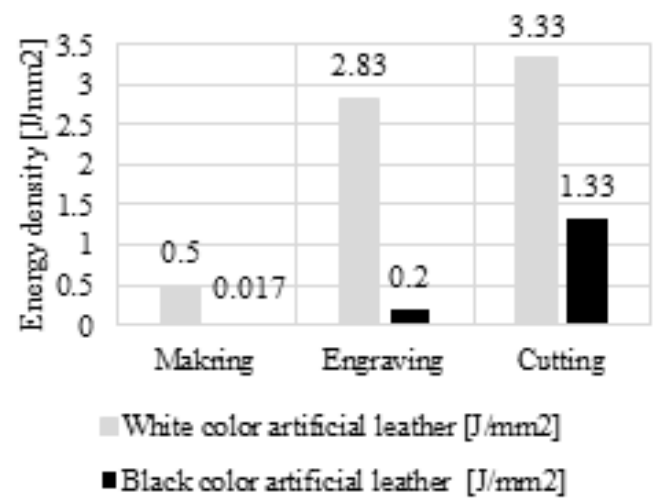

Fig. 19. Values of energy density required for maring, engraving and cutting of black and white color artificial leather using fiber laser plotted in chart. 


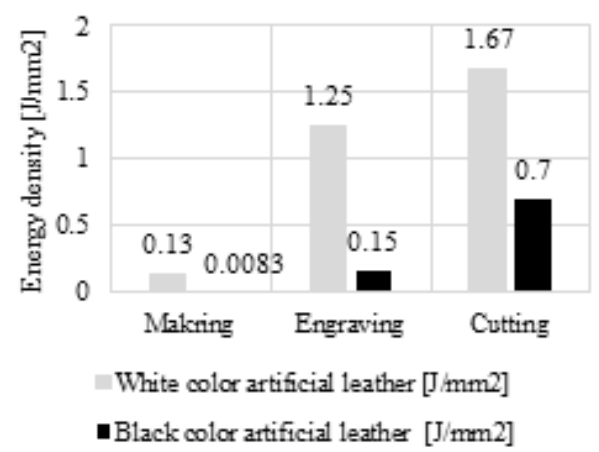

Fig. 20. Values of energy density required for marking, engraving and cutting of black and white color artificial leather using $\mathrm{CO}_{2}$ laser plotted in chart.

In this study it was noted that until the artificial leather base is not subjected to any change by laser scanning ultimate tensile strength properties remains the same. It means that artificial leather tensile strength fully depends on the mechanical properties of the base layer no matter the condition of PVC/PU coating. Applied study results could be observed in Fig. 19.

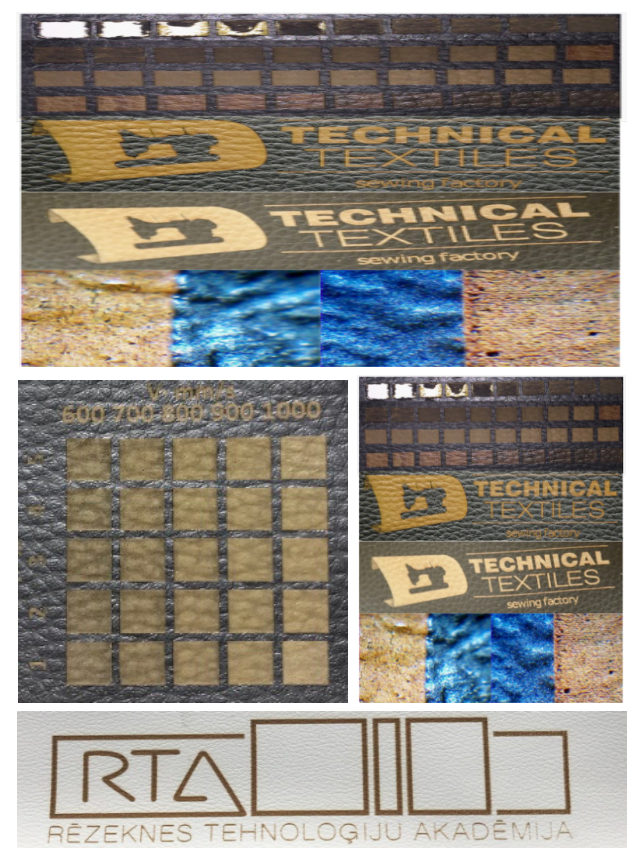

Fig. 21. Laser treatement of black and white color artificial leather.
In conclusion, this study is not last in the coming series of future articles where features of laser processing will be studied for such specific material and others. At this moment RTA laser technology laboratory with "Laser technologies" Masters students and students from "Design" faculty are working on very various topics, trying to find more and more applications and optimizing already known processes for coherent, monochromatic laser light and material interaction.

\section{REFERENCES}

[1] "Global and China Industrial Laser Industry Report 2018-2022" Research In China, ID: 4585808, July 2018.

[2] W. M. Steen, Laser Material Processing. Berlin: Springer-Verlag, 1991.

[3] W. C. M. Leslie, Textile Printing. Machester: Department of Textiles, University of Manchester Institute of Science and Technology, 2003.

[4] Ruowang Liu, Yi Chen, Haojun Fan, Design, Characterization, Dyeing Properties, and Application of Acid-Dyeable Polyurethane in the Manufacture of Microfiber Synthetic Leather, Fibers and Polymers, September 2015, Vol.16, Issue 9, pp 1970-1980, [Online]. Available: https://link.springer.com/article/10.1007/ s12221-015-5024-4

[Accessed March 7, 2019] https://doi.org/10.1007/s12221-015$\underline{5024-4}$

[5] Gail Baugh, The Fashion Designers Textile Directory. Thames \& Hudson LTD, London, 2011

[6] Case Study: Inspires innovation of new, more sustainable faux leather [Online]. Available:

https://www.exxonmobilchemical.com/en/library/asset/bf9707c29913473d9e48d7691eab2030 [Accessed March 9, 2019]

[7] $\mathrm{Xu} \mathrm{Xu}, \mathrm{Wu}$ Zhiping, Environmental Cost Analysis and Upgrading Research of Synthetic Leather Industry Available online at www. sciencedirect.com Energy Procedia 5 (2011) 1341-1347 [Online]. Available: https://www.sciencedirect.com/science/article/pii/ S1876610211011684 [Accessed March 7, 2019]

[8] Artificial leather - Imitation leather, [Online]. Available: https:// www.leatherdictionary.com/index.php/Artificial leather - Imitation leather [Accessed March 10, 2019] 